\title{
ASSESSING THE PURCHASE INTENTION OF MALAYSIAN GENERATION Y IN MOBILE SHOPPING
}

\author{
Zuhal Hussein \\ Faculty of Business Management, Universiti Teknologi MARA, Kota Bharu Campus, Wisma KUB, \\ Jalan Sultan Ibrahim, 15050, Kota Bharu, Kelantan, Malaysia \\ zuhal@kelantan.uitm.edu.my
}

\begin{abstract}
Generation $\mathrm{Y}$ is known as Millennials and also acknowledged as sophisticated and technology wise for which the internet became their forte. With the advancements of Internet technology especially the usage of smartphone to shop online, mobile shopping in this generation is significant and critical for exploration. While a large number of mobile phone consumers are connected to the Internet, it is also variety of online promotion appears aggressively to attract the customers'. As such research on what drives consumers to purchase online has typically been fragmented. In Malaysia setting, it is reported that- mobile phone users were dominated by generation $Y$ users. As the reports indicate, users fully embrace the concept of getting connected everywhere at any time. With pattern showing increasing consumer subscriptions for mobile data usage, it thus indicates the importance of the purchase intentions of online users among Gen $Y$. The aim of this paper is to model the effect of the Gen $Y$ consumers' usefulness, ease of use and enjoyment of their online behaviours on mobile purchase intention. This research is to propose that when Gen $Y$ consumers shop online through mobile applications, their behaviour such as perceived usefulness, perceived ease of use and perceived enjoyment are the important factor to influence the consumer's intention. To test this proposition, one hundred and sixty usable responses were collected using non-probability sampling. The conceptual model was tested using correlation and regression analysis. The findings show that the effect of a consumer's perception on the usefulness, ease of use and enjoyment of mobile shopping towards purchase intentions were significant. We conclude that Gen $Y$ has a strong influence on mobile purchase intentions. Research implications, limitations and suggestions for future researches were also discussed.
\end{abstract}

Keywords: Gen Y, usefulness, ease of use, enjoyment and mobile purchase intention.

\section{INTRODUCTION}

Simply installing a mobile application on a smartphone allows users access to mobile commercial services, such as mobile shopping, mobile banking, mobile investing, and mobile auctions. A study by Arpaci, Yardimci, Özkan, \& Türetken (2012) estimated that online shopping done from mobile phone applications worldwide are expected to grow to US $\$ 119$ billion in 2015 , representing approximately $8 \%$ of the total e- 
commerce market. Despite the initial high expectations of substantial growth, the market has taken much longer than expected to accept mobile commerce (Khalifa \& Shen, 2008). Therefore, further investigations are needed as the creation of a successful and widely adopted mobile commerce environment continues to be difficult to achieve (Herndon, 2013).

However, with the explosive increase in terms of ownership of smartphones, has shown the potential for outburst in mobile shopping (Tsai \& Ho, 2013). It has therefore become important to understand the key factors affecting the success of users' online purchase intention through the use of mobile shopping applications. As this mobile shopping application provides great convenience and unrestricted from temporal and spatial constraints to users that may promote their usage. With the increasing popularity of mobile shopping application, there will probably be a change in the trend of the generation $Y$ consumers who are busy and always connected online. As such generation $Y$ consumers have aroused the interest of global marketers due to their spending power and high likelihood to engage in impulse buying behaviours (Khan et al., 2016).

Generation $\mathrm{Y}$ is made up of an early group of users with the frequent exposure to the technology that has an effect in terms of cognitive and emotional outcomes (Immordino-Yang et al., 2012). Evidence from the report by CNN states that "Americans used smartphone and tablet apps more than PCs to access the Internet (in January 2014)" which is the first time that has ever happened. In the same year another report made by Cohen (2014) stated that $87 \%$ of generation $Y$ always had their smartphones at their side, day and night, $78 \%$ spend over 2 hours a day using their smartphones, and $68 \%$ of generation $Y$ considers their smartphone to be a personal device. Thus, the facts stated above convey the importance of mobile shopping to generation $\mathrm{Y}$ and highlights the need for further study to be conducted.

Based on past studies discussed above regarding mobile users' behavior, most of the researches have attempted to investigate the factors that can influence the purchase intention, where many of these studies are carried out mainly in countries such as the China, Taiwan and USA. Therefore, further research is needed to examine the different influences on the formation of beliefs regarding the usefulness, ease of use, and enjoyment, this given to the facts that belief recurrence in theoretical models of consumer behavioral intentions towards online purchases base on Malaysia setting. In Malaysia setting, a survey conducted by Malaysian Communications and Multimedia Commission (MCMC) in 2014 reported that mobile phone users were dominated by young adults (generation Y), from the age group of 20-24 with 18.8\% users. The second largest group was aged 25-29 which accounted for 16.3\% from the total population in which both groups can be classified as generation $\mathrm{Y}$. Likewise; this report is consistent with another survey by MCMC on Internet Users in 2014, which stated that smartphones were the most widely-used devices to access the Internet at $74.3 \%$. As the numbers indicate, users fully embrace the concept of getting connected everywhere at any time. With pattern showing increasing consumer subscriptions for mobile data usage, it thus indicates the importance of the purchase intentions of online users (Goldsmith, 2002; Bobbit and Dabholkar, 2001).

\section{LITERATURE REVIEW}

Evolvement in the mobile shopping environment had impact the users impressively. It is doubtlessly will contribute to the higher number of users in the future (Forge et al., 2006; Funk, 2004). Study by Wong et al. (2012, p. 25) regard mobile shopping as "any monetary transactions related to purchases of goods or services through internet-enabled mobile phones or over the wireless telecommunication network". Also most of the previous studies postulate that mobile shopping as an advanced of mobile service that allows customers to browse or purchase products and services from retailers via mobile devices anywhere, anytime (Hung et al., 2012; Yang and Kim, 2012).

\subsection{Intentions toward mobile shopping}

Behavioural intentions have been well-established as a strong predictor of actual usage of information technologies (e.g. Davis et al., 1989 and Venkatesh et al., 2003) and of online shopping (e.g. Ajzen, 2011, Lin, 2007; Pavlou and Fygenson, 2006). Perhaps the interactive medium download on mobile shopping application is important characteristics to increase vulnerabilities and generate perceptions that adversely affect the consumers' intention to purchase (Faqih, 2013). Therefore to confirm Fishbein's behavioral intentions model this study is to test its predictability in the context of mobile shopping intention.

Mobile shopping is seen to have an influence to the users' cognitive responses toward using the technology that will influence users' intention (Koufaris, 2002). It is assumed that intentions capture the motivational factors that influence behaviour and the stronger the intention to engage in behavior (Ajzen, 1991). Thus base on past research, this study is to focus on the most commonly referenced online behavioral intentions - 
intention to purchase- as these relate more directly to successful mobile shopping and have been corroborated in several studies.

\subsection{Factors affecting the Users Intention to Purchase}

In evaluating the technology past studies are theorized by models such as the technology acceptance model (TAM; Davis et al., 1989), the theory of reasoned action (TRA; Fishbein and Ajzen, 1975), and the theory of planned behavior (TPB; Ajzen, 1985). The application of this model are differs base on the research perspectives.

Past studies included various frameworks and models to clarify the factors or determinants influencing the acceptance of technology in consumer context. TAM proposed that perceived usefulness and perceived ease-of-use and perceive enjoyment are able to predict the behavioral intention among the mobile technology users. There are several researches done in Malaysia relating to TAM (Hussein, 2015; Krishanan, Khin \& Teng, 2015; Salman et al., 2014; Lim \& Ting; 2012). The TAM model was used to guide this study to identify on the online mobile users' purchase intentions, and their antecedents.

\subsection{Perceive Usefulness}

Perceive usefulness act as a persuasive tool that will increase the influences on mobile users' intention towards usage. Davis (1989, p.320) postulates that "perceived usefulness is the extent to which a person believes that using a particular system will enhance his or her performance". In this study, perceived usefulness signifies the degree to which a user believes that making purchases via smartphone will improve his or her performances.

An individual judgment of perceived usefulness may serve as a key antecedent of a behavioral intention as supported in prior studies (Hussein, 2015; Krishanan et al, 2015; Ha et al, 2007). Apparently, perceived usefulness induces intention to use mobile shopping among young people at the age between 18-24 years in Australia (Sweeney \& Fenech, 2004). Current research done by Ramesh (2013) reported that people at youth age preferred to do mobile purchase because of the usefulness, practicality, durability and performance of the brand. Therefore, this study postulates;

$\mathrm{H1}$ : There is significant relationship between perceived usefulness and intention to purchase in mobile shopping among Gen $Y$

\subsection{Perceive Ease of Use}

Perceived ease of use has been defined by Davis (1989, p. 320) as "the degree to which a person believes that using a particular system would be free of effort". Prior studies on consumer behavior found that a consumer's perceived ease of use and perceived usefulness of a system affect behavior intention of the consumer toward the system (Gao \& Bai, 2014; Li, 2013). Ease of use tells that how simple it is to use the Internet as a shopping channel (Monsuwe et al., 2004). For generation $Y$, if they believe that they can easily handle the process of online shopping and it does not require additional efforts of developing skills that is needed to complete the process, they are more prone to do online shopping (Chiu et al., 2009). In short, the ease of use of online mobile purchase platforms may induce the Gen Y consumers' mobile online purchase intention in the future. Therefore, we hypothesize;

$\mathrm{H} 2$ : A consumer of Gen Y perceived ease of use of mobile shopping positively affects their intention to use

\subsection{Perceive Enjoyment}

Enjoyment is to arise resulting from the fun and play arising from the mobile shopping experience. Mobile shoppers can be described as "problem solvers", and can be termed seeking for "fun, fantasy arousal, sensory stimulation, and enjoyment" (Hirschman and Holbrook, 1982). In the interactive environment of shopping experience, perceive enjoyment is expected to play the most prominent psychological impact (Lombard and Ditton, 1997). Likewise, several studies have established the positive influence of enjoyment as an essential factor in online shopping (Eighmey, 1997; Jarvenpaa and Todd, 1997).

Enjoyment has been defined as the extent to which using a system is perceived to be enjoyable in its own right, apart from any performance consequences that may be anticipated (Carroll, 1988, Cheema et al., 2013). Davis et al. (1992) classified enjoyment as an intrinsic motivation for adopting technology. This perception is an intrinsic motivation to use a certain information system (Rehman et al, 2013). 
Enjoyment was also shown to induce perceptions of ease of use with subjects, thus enhancing technology adoption (Venkatesh, 2000). In this study, user's perceived enjoyment refers to the extent to which users expect to derive pleasure, fun and joy from using mobile shopping.

Consumers are unlikely to visit a website if it doesn't load properly on their mobile devices and do not experience a feeling of joy, elation, fun and pleasure and gratification from mobile shopping (Chinomona, 2013). In which there is a need for further study on this statement. Where there is remarkably little other research linking to enjoyment, perhaps because this effect is taken for granted (Lombard and Ditton, 1997). Therefore it is critical for this study to identify user's belief on purchase intention base on factors of enjoyment. Thus, the following hypothesis is proposed:

H3: Enjoyment will positively affect Gen Y consumer's intention to purchase in mobile shopping.

\section{METHODOLOGY}

This quantitative research using an experimental method employed 160 respondents of generation $Y$ selected to participate on this research. As stressed by Bolton et al. (2013), using generation Y respondent in the research is an ideal group to focus on. This is based on technological settings which seem to be scarce, where its determinants may differ significantly.

As such university students and a self-administered survey were used for data collection through convenience sampling. University students were selected because their behaviors may change over their life cycle stages to infer generation Y's technological use. Therefore, it is vital for this research to study the mobile shopping experience among generation Y. By using university students as a sample, the fact that their behaviors are likely to vary in different contexts can be identified.

A questionnaire was used as an instrument to gather the data for this study. The questionnaire contains two main parts, the first relating to information about respondents' demographic characteristics. The second part was designed to measure respondents' knowledge and their mobile shopping experience. SPSS version 16 was used to analyze the data in this study.

\section{RESULTS}

Frequency analysis was first run to measure respondents' demographic characteristics. The results of analysis were presented in Table I. The ratio between male and female was not balance, which were $71.2 \%$ female and $28.8 \%$ male. The imbalance ratio was due to the fact that majority of the university students were female. Majority of the respondents fell into age group 26-30years old, which was $75.0 \%$, followed by $21-25$ years old (12.5\%), 31-35 years old (8.7\%), 36-40 years old (2.5\%) and lastly $18-20$ years old (1.3\%). In terms of source of financing, majority of them were using money on loan basis $(66.9 \%)$, own income and family basis (17.5\%), followed by scholarship basis (13.1\%) and lastly from a part time job $(2.5 \%)$.

Table 1: Socio Demographic Background

\begin{tabular}{|l|l|c|c|}
\hline $\begin{array}{c}\text { Demographic / } \\
\text { Social Variables }\end{array}$ & Categories & Frequency & Percentage (\%) \\
\hline Gender & Male & 46 & 28.8 \\
& Female & 114 & 71.2 \\
\hline Age (Years) & $18-20$ & 2 & 1.3 \\
& $21-25$ & 20 & 12.5 \\
& $26-30$ & 120 & 75.0 \\
& $31-35$ & 4 & 8.7 \\
& $36-40$ & 21 & 2.5 \\
\hline Source of financing & Scholarship & 107 & 13.1 \\
& Loan & 66.9 \\
& Own/Family & 28 & 17.5 \\
& Part time job & 4 & 2.5 \\
\hline
\end{tabular}


Table 2: Coefficient Correlations

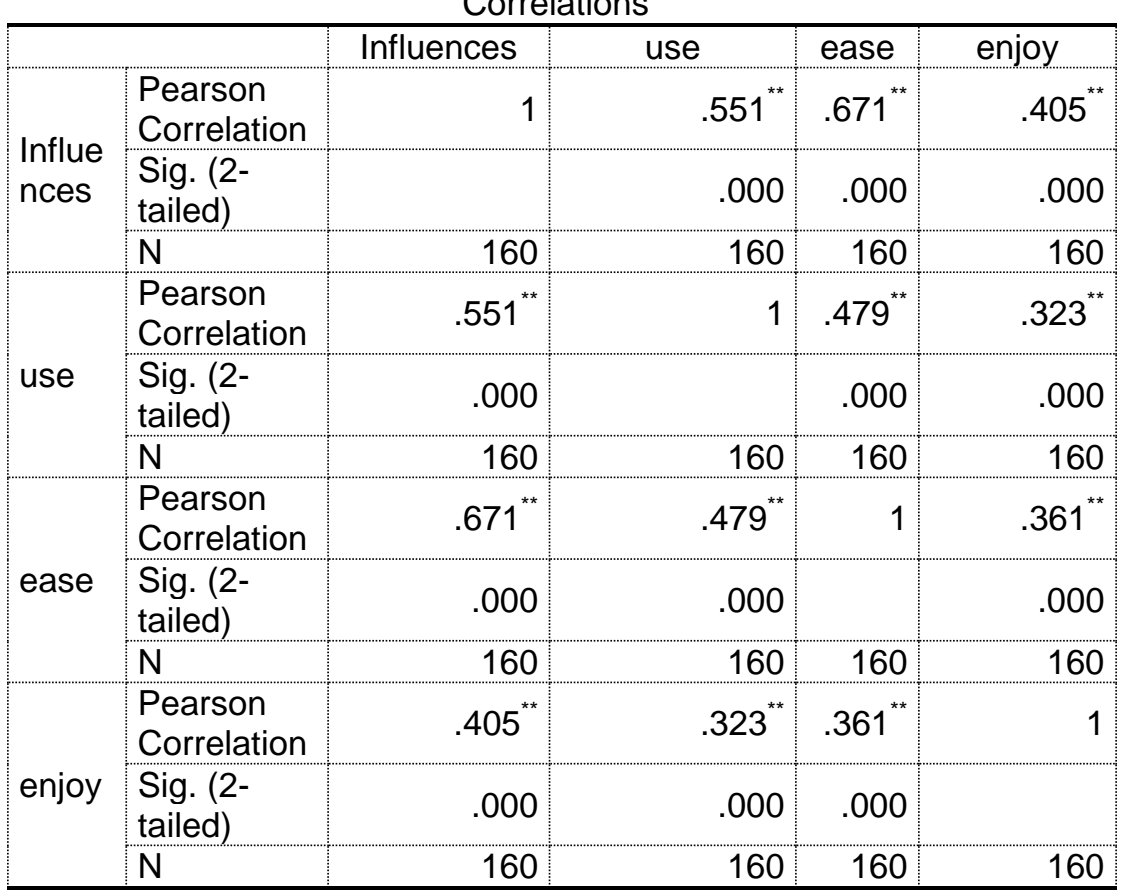

${ }^{* *}$. Correlation is significant at the 0.01 level ( 2 tailed).

The result of Pearson Correlations from the table 2 above shows that perceived ease of use (PEOU) is having a good relationship with influence of online shopping with the highest correlation $r=.671$. While perceived usefulness (PU) influenced online shopping with a correlation of $r=.551$. Perceived enjoyment is having a moderate relationship with the intention to do mobile shopping with the lowest correlation of $r=.405$.

Table 3: Regression analysis

\begin{tabular}{|l|l|l|l|l|l|l|}
\hline \multirow{5}{*}{ Model } & \multicolumn{2}{|l|}{$\begin{array}{l}\text { Unstandardize } \\
\text { d Coefficients }\end{array}$} & $\begin{array}{l}\text { Standardized } \\
\text { Coefficients }\end{array}$ & & \\
\cline { 2 - 5 } & $\beta$ & Std. Error & Beta & $\mathrm{t}$ & \multirow{2}{*}{ Sig. } \\
\hline \multirow{2}{*}{1} & Constant & .179 & .261 & & .687 & .493 \\
\cline { 2 - 5 } & PU & .285 & .067 & .271 & .287 & .000 \\
\cline { 2 - 5 } & PEOU & .534 & .070 & .490 & .642 & .000 \\
\hline & PE & .125 & .053 & .141 & .371 & .019 \\
\hline
\end{tabular}

Dependent Variable: Intention

Based on the result above, perceived usefulness (PU) with $p$-value $=.000$ and perceived ease of use (PEOU) with $p$-value $=.000$ are significant with behavioral intention. Perceived enjoyment (PE) also found to be significant with behavioral intention with $p$-value $=.019$. The result also found that PEOU was the most important factor that contributes to behavioral intention with the highest value of $\beta=.534$ and followed by PU factor with $\beta=.285$ and $P E$ factor with $\beta=.125$. The results indicate that they have a positive relationship with each other.

\section{DISCUSSION AND CONCLUSION}

From the above findings, it shows that those 3 factors; perceived usefulness, perceived ease of use and perceived enjoyment were significant with the purchase intention on mobile shopping. Perceived ease of use 
was the most important factor that influenced the purchase intention with regards to mobile shopping. This is due to the fact that Gen Y prefers to use a technology which is user friendly, practical and not complicated when carrying out mobile shopping. This result was supported by a previous study done by Bigné et al. (2007), who posited that younger users tend to use the Internet shopping sites more than older users, when they found it easy and practical to use. In addition, Ramesh (2013) reported that young people preferred to do mobile purchase because of the usefulness, practicality, durability and performance of the brand.

Perceived usefulness was found to be significant in this study, because in any study of the online purchase intention technology, this variable is the key antecedent that influences the behavioral intention (Hussein, 2015; Krishanan et al, 2015; Ha et al, 2007). Since this study focuses on Gen Y, we can see that the users are more prone to do mobile purchases because they find the system is useful, practical, durable (Ramesh, 2013) and effortless (Chiu et al., 2009) for performing the task.

Based on the results of perceived enjoyment, it was concluded that generation $Y$ mobile shoppers are more likely to be out shoppers and are likely to derive more enjoyment from shopping. This result was consistent with prior studies where it was discovered that users found mobile shopping enjoyable, fun and pleasurable (Hirschman and Holbrook, 1982, Chinomona, 2013) and perceived enjoyment has a positive effect on mobile purchase intention (Karasavvogloua et al., 2013).

In conclusion, this research can be useful for future researches in mobile shopping. It updates the knowledge of the behavioral intention to purchase in mobile shopping. Besides that, the findings of this study would provide an insight to retailers and mobile application developers who intend to venture or expand into the Malaysian market to get a better understanding of behavior and expectations of Malaysian Generation $Y$ in mobile shopping. Apart from that, to target the Generation $Y$ effectively, marketers must have a unique way of segmenting the market by being aware of constantly changing the behaviour and trends in this generation.

\section{LIMITATIONS}

This study has several limitations which offer avenues for further research. First, the number of samples is relatively small to represent the population of Malaysian generation $Y$ due to financial and time constraints in recruiting the respondents. Secondly, the conceptual framework needs a larger set of variables to intensively study the effects, and this can be materialized by future studies of consumer behavior with regards to mobile shopping.

\section{REFERENCE LIST}

Arpaci, I., Yardimci, Y., Özkan, S., \& Türetken, Ö. (2012). Organizational adoption of mobile communication technologies. European, Mediterranean \& Middle Eastern Conference on Information Systems.

Munich, Germany. Retrieved 2nd December 2014 from http://www.iseing.org/emcis/emcis2012/EMCISWebsite/proceedings/146.pdf

Khalifa, M. \& Shen, K. 2008, 'Explaining the adoption of transactional B2C mobile commerce', Journal of Enterprise Information Management, vol. 21, no. 2, pp. 110-124.

Herndon, N. C. (2013). A Retrospective/Perspective/Prospective Look at Marketing Channels. Journal of Marketing Channels, 20(3/4), 185-190. http://dx.doi.org/10.1080/1046669X.2013.803422

Tsai, J. P., \& Ho, C. F. (2013). Does design matter? Affordance perspective on smartphone usage. Industrial Management \& Data Systems, 113(9), 1248-1269. http://dx.doi.org/10.1108/IMDS-04-2013-0168

Khan, N., Lai, H.H., Chen, T.B. \& Hoe, H.Y.(2016). Impulse Buying Behaviour of Generation Y in Fashion Retail. International Journal of Business and Management; 11(1)

Immordino-Yang, M. H., Christodoulou, J. A., \& Singh, V. (2012), "Rest is not Idleness: Implications of the Brain's Default Mode for Human Development and Education", Perspectives on Psychological Science, Vol. 7 No. 4, pp. 352-364.

Cohen, H. (2014). 55 US Mobile Facts Every Marketer Needs for 2015.

Malaysian Communications and Multimedia Commission. (2014) 
Bobbitt, L.M. \&Dabholkar, P.A. (2001). Integrating attitudinal theories to understand \& predict use of technology-based self- service: the internet as an illustration. International Journal of Service Industry Management, 12(5), 423-50.

Goldsmith, R.E. (2002). Explaining \& predicting consumer intention to purchase over the internet: an exploratory study. Journal of Marketing Theory \& Practice, 10(2), 22-8.

Funk, J. (2004. Mobile Disruption: The Technologies and Applications that are Driving the Mobile Internet, NY: John Wiley \& Sons.

Hung, M.C., Yang, S.T., \& Hsieh, T.C. (2012). An examination of the determinants of mobile shopping continuance. International Journal of Electronic Business Management, 10(1), 29-37

Yang, K., \& Kim, H. (2012). Mobile shopping motivation: An application of multiple discriminant analysis. International Journal of Retail \& Distribution Management, 40(10), 778-789.

Davis, D. F. (1989). Perceived Usefulness, Perceived Ease Of Use, And User Acceptance Of Information Technology. Mis Quarterly, 13(3), 23.

Venkatesh, Viswanath, Morris, Michael G., Davis, Gordon B., Davis, Fred D. (2013). "User Acceptance of Information Technology: Toward a Unified View," MIS Quarterly, 27, pp425-478

Eighmey, J., (1997). Profiling user responses to commercial web sites. Journal of Advertising Research 37 (3), 59-66

Jarvenpaa, S.L. and Todd, P.A. (1997). "Consumer Reactions to Electronic Shopping on the World Wide Web," Journal of Electronic Commerce, Vol. 1, No. 2: 59-88.

Chinomona, R. (2013). The Influence of Market Related Mobile Activities on the Acceptance of Mobile Marketing and Consumer Intention to Purchase Products Promoted by SMS in South Africa. The Journal of Applied Business Research. 29 (6).

Faqih, K. M. S. (2013). Exploring The Influence Of Perceived Risk And Internet Self-Efficacy On Consumer Online Shopping Intentions: Perspective Of Technology Acceptance Model. International Management Review. Jun2013, 9(1), 11.

Koufaris, M. 2002. "Applying the Technology Acceptance Model and Flow Theory to Online Consumer Behavior," Information Systems Research (13:2), pp 205-223.

Venkatesh, V. (2000). Determinants Of Perceived Ease Of Use: Integrating Control, Intrinsic Motivation, And Emotion Into The Technology Acceptance Model. Information Systems Research, 11(4), 23. Doi: 10.1287/Isre.11.4.342.11872

Hussein, Z. (2015). Explicating students' behaviours of E-learning: A viewpoint of the extended technology acceptance. International Journal of Management and Applied Science, 1 (10), pp 68-73.

Krishanan, D., Khin,A.A \& Teng,L.L.(2015). Attitude towards using online banking in Malaysia. British Journal of Economics, Management and Trade, 7(4), DOI : 10.9734/BJEMT/2015/17660

Salman, A., Mohamad Saleh, M.A., Abdullah, M.Y., Mustaffa, N., Ahmad, A.L.,Kee, C., Saad, S. (2014). ICT acceptance among Malaysian urbanites: A study of additional variables in user acceptance of the new media. GEOGRAFIA OnlineTM Malaysian Journal of Society and Space, 10(6), pp 86 - 96.

Sweeney, A. \& Fenech, T. (2004). M-tailing Among the Young: Exploring Their Intentions to Shop by Mobile Phone.

Gao, L., \& Bai, X. (2014). A unified perspective on the factors influencing consumer acceptance of the Internet and of things technology. Asia Pacific Journal of Marketing and Logistics, 26(2), 211-231. http://dx.doi.org/10.1108/APJML-06-2013-0061.

$\mathrm{Li}, \mathrm{C}$. Y. (2013). Persuasive messages on information system acceptance: A theoretical extension of elaboration likelihood model and social influence theory. Computers in Human Behavior, 29, 264-275. http://dx.doi.org/10.1016/j.chb.2012.09.003.

Venkatesh, V., Davis, F. D., \& Morri, M. G. (2007). Dead of live? The development, trajectory and future of technology adoption research. Information Technology Research Institute, ITRI-WP0840207(3/30/07). 
Chiu, C.M., Chang, C.C., Cheng, H.L., Fang, Y.H. (2009), Determinants of customer repurchase intention in online shopping. Online Information Review, 33(4), 761-784.

Lu, H. P., \& Su, Y. J. P. (2009). Factors affecting purchase intention on mobile shopping web sites. Internet Research, 19(4), 442-458. http://dx.doi.org/10.1108/10662240910981399

Ajzen, I. (1991). The theory of planned behavior. Organizational Behavior and Human Decision Processes, 50(2), 179-211. http://dx.doi.org/10.1016/0749-5978(91)90020-T.

Lombard, M., \& Ditton, T. (1997). At the Heart of It All: The Concept of Presence Journal of Computer mediated Comunication, 3(2), 1-20

Hirschman, E. C. \& Holbrook, M. B., 1982. Hedonic Consumption: Emerging Concepts, Methods and Propositions. Journal of Marketing, 46(3), pp. 92-101.

Rehman,A. Alqahtani, S. Altameem, A. Saba, T. (2013) Virtual Machine Security Challenges: Case Studies, International Journal of Machine Learning and Cybernatics, DOI 10.1007/s13042- 013-0166-4. 